\title{
Editorials
}

\section{Prevention and control of chronic diseases}

BMJ 2010; 341 doi: http://dx.doi.org/10.1136/bmj.c4865 (Published 15 November 2010) Cite this as: BMJ 2010;341:c4865

- Article

- Related content

- Metrics

- Responses

- Peer review

-

\section{Peter Piot, director 1, Shah Ebrahim, professor of public health2}

\section{$\underline{\text { Author affiliations }}$}

peter.piot@Ishtm.ac.uk

A UN General Assembly meeting is a unique opportunity to put them on the world's agenda

Chronic diseases-cardiovascular diseases, cancers, chronic respiratory diseases, and diabetes-are the leading global causes of death. Mental illnesses, injuries, osteoarthritis, and chronic kidney diseases also contribute substantially to disability but are often excluded from consideration. Of 58.8 million deaths globally, $60 \%$ were attributed to chronic diseases in 2004.1 Even in sub-Saharan Africa, where infectious diseases remain the major disease burden, with AIDS as the single leading cause of death, chronic diseases account for $25 \%$ of all deaths. Deaths from chronic diseases are projected to increase dramatically between now and $2030 \underline{\underline{\Perp}} .2$

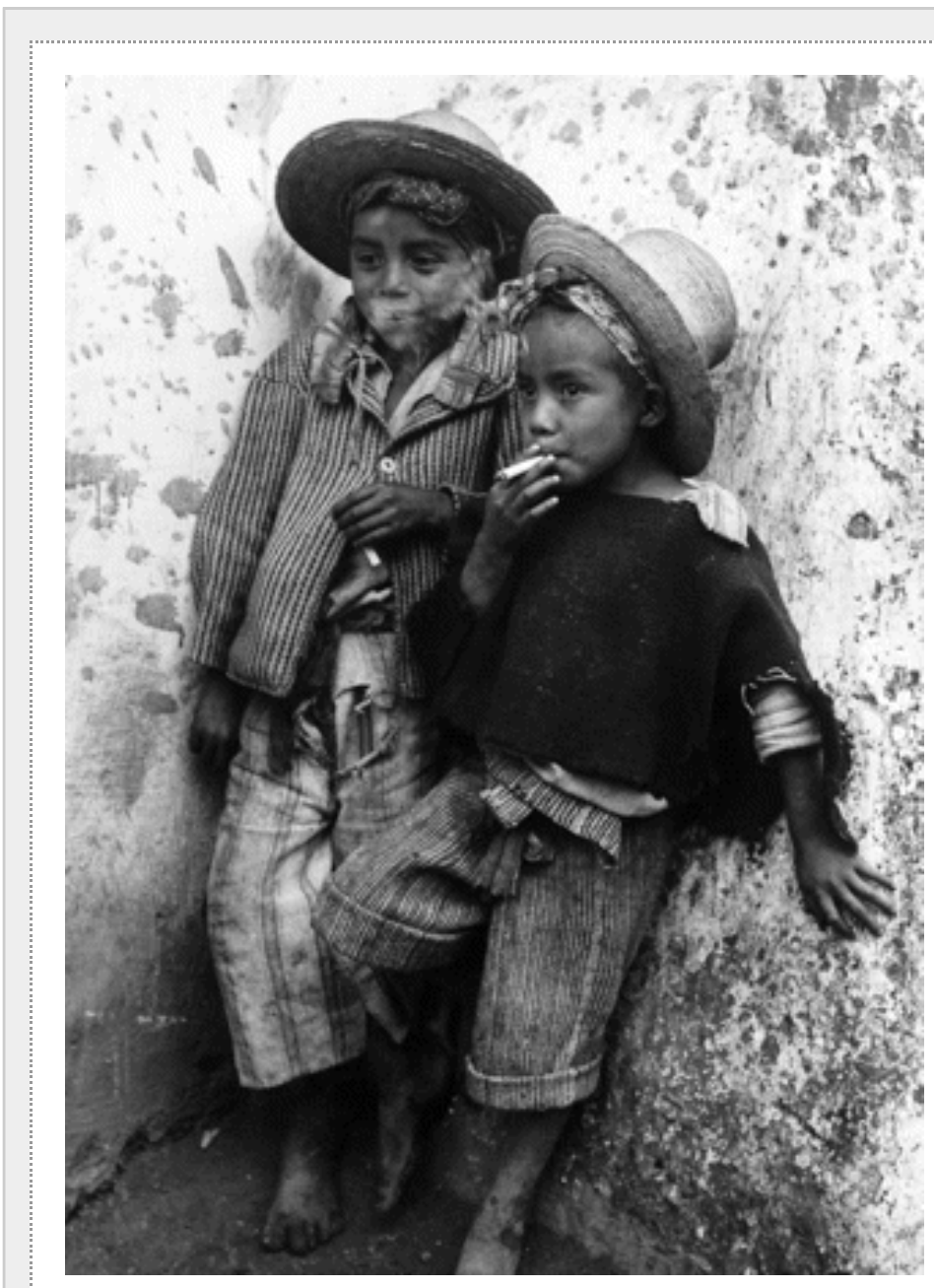

"Hans Namuth/Science Photo Library" 
Chronic diseases are a heterogeneous group but many share underlying causes. Direct causes and risk factors for chronic disease, such as high blood pressure, diabetes, and raised blood lipids, are linked to lifestyle factors - for example, smoking, unhealthy eating, and physical inactivity. Although it is not unusual to blame individuals for their behaviours, societal factors often determine these behaviours. 3 Such factors include the promotion of tobacco; the high levels of saturated and trans-fats, sugars, and salt hidden in processed foods; and urbanisation. Lack of progress on the control of chronic diseases is one of the major obstacles to achieving the health related millennium development goals. 4

Myths about chronic disease have contributed to their neglect. A first myth is that they are "diseases of affluence," which places them outside of a global concern with poverty. In fact, risk factors are socially patterned —rates of smoking are higher in poorer people, and age standardised mortality rates for chronic diseases are almost twice as high in low high income countries than in high income ones. 1 A second myth is that "you have to die from something," and that chronic diseases are not a cause of premature death. In fact, about $60 \%$ of chronic disease deaths in low and middle income countries occur in people aged under 60 years.5 A third myth is that no cost effective interventions exist. In fact, highly cost effective interventions are available to prevent and control common chronic diseases. 6 Tobacco control, together with population wide restriction of salt, would stop 13.8 million premature deaths over 10 years in low and middle income countries and would cost about $\$ 0.5$ (£0.3; €0.4) per person per year.7 Treating people at high risk of cardiovascular disease with aspirin, a statin, and two blood pressure lowering drugs is highly cost effective and would save about as many premature deaths as the population strategies. 8 However, focusing on the distal determinants by means of fiscal and legal mechanisms is more attractive than individual interventions because this can provide a final "fix," whereas individual interventions require continued surveillance, diagnosis, and treatment.

There are many other reasons why chronic diseases have not yet acquired their place at the top of the world's health and political agendas.9 10 These include lack of unified international leadership and of powerful actors and community activists, including people affected by the diseases; lack of a clear and unified strategy, in particular about how to tackle the problem and at what cost; an emphasis on technical debates and on treatment, instead of creating and using favourable political contexts; a lack of documentation and of recognition of the role of chronic diseases in the alleviation of poverty, which is also reflected by their absence from the millennium development goals.11

The decision by the United Nations General Assembly to convene a "high level meeting on the prevention and control of non-communicable diseases worldwide" in September 2011 provides a unique opportunity to elevate chronic diseases to the global political agenda-just as the 2001 UN General Assembly special session on HIVIAIDS was a tipping point in the global response to AIDS.11 However, generating such a paradigm shift for the global response to chronic diseases will require a dramatic change in how they are framed and linked with global development and the alleviation of poverty; a well coordinated alliance across the various disease constituencies (as initiated by the NCD Alliance) and funders (Global Alliance for Chronic Diseases); and a unified strategy including technical consensus on cost effective solutions.

UN sessions tend to pass very general resolutions and agree on grandiose goals, with little accountability. Crucially, therefore, the chronic disease communities must develop as soon as possible the concrete "ask" for this UN session-a platform for action for political negotiation by UN member states. Elements of such a call to action include full and immediate implementation of the Framework Convention on Tobacco Control by all 
member states; endorsement of the World Health Organization's strategy on non-communicable diseases12; regulation of the salt, fat, and sugar content of processed foods; elimination of national and European Union subsidies for harmful crops; and access to essential treatments for the most common chronic diseases, which will require the strengthening of health systems. A strong declaration would set specific goals for reducing the incidence and burden of chronic diseases, and possibly for funding these efforts, as well as committing to public policy audits of health impacts in various sectors such as education, employment, transport, urban and rural development. Lobbying for the specific inclusion of every single disease or for technical elements-as important as they may be-would be counterproductive, because this would risk dividing the field, creating confusion among diplomats, and diverting attention from the core agenda, which by definition is political in the General Assembly.

Finally, besides a unified platform, the road map to a successful high level session requires three forces to work in synergy. Firstly, political champions among the UN member states, including a few permanent representatives in New York who are willing to dedicate a large proportion of their time to the preparation of the session. Secondly, a proactive secretariat in New York within the UN system to support political process and ensure technical accuracy (this may require the appointment by the UN secretary general of a personal representative for 12 months, with support from WHO). And, lastly, a unified activist civil society, comprising not only disease specialists and public health experts, but also businesses and the people directly concerned, such as patients with diabetes and survivors of breast cancer, because such people have been powerful agents in the AIDS movement.

\section{Notes}

Cite this as: BMJ 2010;341:c4865

\section{Footnotes}

- Competing interests: All authors have completed the Unified Competing Interest form at www.icmje.org/coi disclosure.pdf (available on request from the corresponding author) and declare: PP had no support from any organisation and SE had support from the Wellcome Trust for the submitted work; no financial relationships with any organisations that might have an interest in the submitted work in the previous three years; no other relationships or activities that could appear to have influenced the submitted work.

- Provenance and peer review: Commissioned; not externally peer reviewed.

\section{References}

1. $\rfloor W H O$. Global infobase. https://apps.who.int/infobase/Mortality.aspx.

2. $\downarrow$ Mathers CD, Loncar D. Projections of global mortality and burden of disease from 2002 to 2030. PloS Med2006;3:e442. CrossRef Medline

3. Ebrahim S, Smeeth L. Non-communicable diseases in low and middle-income countries: a priority or a distraction? Int J Epidemio/2005;34:961-6. FREE Full Text

4. $\downarrow$ Stuckler D, Basu S, McKee M. Drivers of inequality in Millenium Development Goal progress: a statistical analysis. PLoS Med2010;7:e1000241. CrossRef Medline

5. $\lrcorner$ Beaglehole R, Ebrahim S, Reddy KS, Voute J, Leader S; on behalf of the Chronic Disease Action Group. Prevention of chronic diseases: a call to action. Lancet 2007;370:2152-7. Medline Web of Science 
b. $\lrcorner$ Asarıa $P$, C UıshoIm $D$, Mathers $C$, Łzzatı M, Beaglenole $K$. Chronıc dısease preventıon: health ettects and tınancial costs of strategies to reduce salt intake and control tobacco use. Lancet2007;370:2044-53. CrossRef Medline Web of Science

7. $\downarrow$ Lim SS, Gaziano TA, Gakidou E, Reddy KS, Farzadfar F, Lozano R, et al. Prevention of cardiovascular disease in high risk individuals in low and middle-income countries: health effects and costs. Lancet 2007;370:2054-62. CrossRef Medline Web of Science

8. $\downarrow$ Shiffman J, Smith S. Generation of political priority for global health initiatives: a framework and case study of maternal mortaility. Lancet 2007;370:1370-9. CrossRef Medline Web of Science

9. $\downarrow$ Sridhar D, Batniji R. Misfinancing global health: a case for transparency in disbursements and decision making. Lancet 2008;372:1185-91. CrossRef Medline Web of Science

10. $\downarrow$ Institute of Medicine. Promoting cardiovascular health in the developing world: a critical challenge to achieve global health. 2010. www.iom.edu/Reports/2010/Promoting-Cardiovascular-Health-in-the-Developing-World-A-CriticalChallenge-to-Achieve-Global-Health.aspx.

11. $\downarrow$ United Nations General Assembly Special Session on HIVIAIDS 25-27 June 2001. Declaration of commitment on HIVIAIDS. 2001. http://data.unaids.org/publications/irc-pub03/aidsdeclaration en.pdf.

12. $\downarrow \mathrm{WHO}$. Action plan for the Global Strategy for the Prevention and Control of Noncommunicable Diseases 2009-2013. WHO, 2008.

\section{Article tools}

\section{3 responses}

- ש̈Respond to this article

- BPrint

- Alerts \& updates

\section{Article alerts}

Please note: your email address is provided to the journal, which may use this information for marketing purposes.

\section{Log in or register:}

$$
\begin{aligned}
& \text { Username * } \\
& \text { Password * } \\
& \text { Log in }
\end{aligned}
$$

$\underline{\text { Register for alerts }}$

(1) If you have registered for alerts, you should use your registered email address as your username - Oitation tools

\section{Download this article to citation manager}

